\title{
Entrepreneurship Research: Which Trails to Blaze Next
}

\author{
Holger Patzelt (TUM Entrepreneurship Research Institute)
}

KEYWORDS: Educational Services, Entrepreneurship, Research Methods.

The community of entrepreneurship researchers has grown rapidly over the past few decades, and the quality and variety of entrepreneurship research has increased dramatically. As a result, a wealth of information about entrepreneurial phenomena is available today, benefiting both those who study it and those who practice it. But in our new open access book, we suggest that while entrepreneurship researchers can celebrate their contributions to the field so far, they shouldn't bask in the limelight too long.

Trailblazing in Entrepreneurship: Creating New Paths for Understanding the Field (free download here(https://drive.google.com/open?id=0B8gg18ojhw_SzZWcHc2Y0JZQWM) ) by Dean A. Shepherd from Indiana University and Holger Patzelt from the Technical University of Munich, applies the saying "dance with the one who brung you" to suggest that behind successful entrepreneurship research are researchers who are entrepreneurial themselves. They need to stick with this entrepreneurial approach to continue generating knowledge at the same pace. That means blazing new trails.

The book also suggests which areas of entrepreneurship are ripe for new trails, how to begin them, and where they might lead. Specifically, it offers a series of frameworks for generating important research that will have a substantial impact on the understanding of entrepreneurial phenomena and, in turn, can inform future entrepreneurship research.

It covers these aspects of trailblazing:

(1) generating, refining and exploiting potential opportunities and the benefits generated for the entrepreneur (and/or the entrepreneurial firm) and/or others,

(2) extending the notion of the "potential" opportunity to recognize that failure, a frequent outcome of entrepreneurial action, can benefit the entrepreneur, the

entrepreneurial firm and/or others primarily through learning from the experience,

(3) combining the operational processes of innovation and the various aspects of the entrepreneurial process to provide a deeper explanation of entrepreneurial activities and outcomes,

(4) viewing the entrepreneurial process as being embedded in the natural environment and sustainable development,

(5) focusing on entrepreneurs' relational environment in terms of the family's role in entrepreneurial businesses,

(6) acknowledging that an exploration of entrepreneurs' personal physical environments can yield a deeper understanding of how health impacts entrepreneurial action and how entrepreneurial action impacts health (of the entrepreneur and/or others), and

(7) making explicit the role of decision making by explaining how entrepreneurial decision-making research can help blaze new trails in the field of entrepreneurship.

As these important directions for trailblazing illustrate, it is not a time for entrepreneurship researchers to rest on their laurels but to push ahead. 